\title{
Energy efficiency and appliance's characteristics considered prior to purchase: Differences and similarities between the United Kingdom, Germany, Portugal, Greece, Poland, Spain and Italy
}

\section{Rui Gaspar \& Dalila Antunes}

To cite this article: Rui Gaspar \& Dalila Antunes (2016) Energy efficiency and appliance's characteristics considered prior to purchase: Differences and similarities between the United Kingdom, Germany, Portugal, Greece, Poland, Spain and Italy, International Journal of Green Energy, 13:6, 546-555, DOI: 10.1080/15435075.2014.962033

To link to this article: http://dx.doi.org/10.1080/15435075.2014.962033

Accepted author version posted online: 27

Oct 2014.

Published online: 27 Oct 2014.

Submit your article to this journal

Џ Article views: 64

View related articles $\sqsubset$

View Crossmark data ־ 


\title{
Energy efficiency and appliance's characteristics considered prior to purchase: Differences and similarities between the United Kingdom, Germany, Portugal, Greece, Poland, Spain and Italy
}

\author{
Rui Gaspar (1) ${ }^{\mathrm{a}, \mathrm{b}}$ and Dalila Antunes ${ }^{\mathrm{c}}$ \\ anstituto Universitário de Lisboa, ISCTE-IUL, Cis-IUL, Lisbon, Portugal; bWilliam James Center for Research, ISPA-Instituto Universitário, Lisbon, \\ Portugal; 'Factor Social, Lda.-Consultancy in Psychosociology and the Environment, Lisbon, Portugal
}

\begin{abstract}
This article reports country differences in the consumer's most considered characteristics when choosing electrical appliances, including but not restricted to the energy efficiency aspect. A survey was performed to store customers from 7 countries: the United Kingdom; Germany; Portugal; Greece; Poland; Spain; Italy. Results showed consistency between countries in the top three characteristics considered: cost; quality; and a balance between price and quality. Differences were found for reported environmental attitudes and behaviours, purchase motives, and store employees evaluation. The results may support national policies and store level energy efficiency interventions. Specifically, they can provide input for store employee's training, in persuading customers towards the purchase of energy efficient appliances.
\end{abstract}

\section{KEYWORDS}

Decision making efficiency; electrical appliances choice; country comparison

\section{Introduction}

European energy policy pinpoints the importance of reducing energy consumption at home, namely considering the Horizon 2020 strategy and Energy Roadmap 2050 documents. Emphasis on technology is quite evident regarding building technology, appliances' technology and energy consumption monitoring tools. However, despite an increase in the number of energy efficiency measures in the last decade, research data has shown that energy consumption has risen in the EU27 (e.g. in the tertiary sector, as shown by Bertoldi and Atanasiu 2008 and 2007), although there are some optimistic results showing that energy efficiency measures may be starting to reduce this trend may (see Atanasiu and Bertoldi 2010; Bertoldi and Atanasiu 2011).

Nonetheless it is important to acknowledge that the existence of technology does not induce change on its own. It is necessary that stakeholders (e.g. constructers) and consumers buy and use that technology in a way that allows enhancing the most, its potential. Hence, complimentary efforts in developing technology should be focused on making sure that it reaches households and is embraced by people on their daily habits, as long as a number of barriers to and constraints on this behavioral change are overcome (see e.g. Bertoldi and Atanasiu 2008; Gaspar 2013). This problem can be addressed through technical solutions (e.g. as in the case of renewable energy use; see e.g. Haar and Theyel 2006) but it should also be resolved through changes in consumers behaviors, so that these technical solutions potential is used at its highest level. Accordingly, in order to achieve the best results in terms of energy saving and comply with carbon emission commitments, consumers, services (including retail sales staff) and government/policy makers all need to work together (Gaspar and Antunes 2011). On one side, this demands that consumers should be provided with effective information and tools. These should allow a behavior change and the development of an increased energy saving competency, so that they can inhibit/reduce barriers that prevent them from acting in a sustainable way (Gaspar, PalmaOliveira, Corral-Verdugo 2010; Gaspar 2013). On another side, this demands that the retail staff (for example, appliances store employees), policy makers, and other stakeholders, should be provided with the relevant information to intervene, e.g. at the moment of the energy appliances purchase, so that they increase the probability that class A appliances ${ }^{1}$ are purchased.

However, it should be taken into consideration that policies devised at a global level-e.g. European Union (EU27)should also take into consideration the specificities that exist at the country, city and/or local levels. In fact, these specificities may imply different levels of success when policy makers and other stakeholders need to implement energy efficiency programs and global policies at a national/regional/local level (see Roosa 2007). In a previous article (Gaspar and Antunes 2011) we aimed at providing contributions for a European wide policy with regard to domestic electrical appliances purchase and use, by defining typologies of consumers (based on socio-demographic and psychosocial characteristics) and the predictors of consideration of energy efficiency when purchasing an appliance. Differently, in this article, we will aim to provide contributions at the national level, considering the specificities of seven European countries, namely the differences and similarities between them. This will be

CONTACT Rui Gaspar rgaspar@ispa.pt E William James Center for Research, ISPA-Instituto Universitário, Rua Jardim do Tabaco no, 34 - $1149-041$ Lisboa, Portugal.

(c) 2016 Taylor \& Francis Group, LLC 
with regard to factors that consumers consider when choosing an appliance (including the energy efficiency class and other aspects) and differences in a set of socio-demographic and psychosocial factors that may influence consumers' choice (e.g. environmental attitudes and behaviors) which may also influence their decisions. In our view, this can allow policy makers and other stakeholders to devise both European wide initiatives (see based Gaspar and Antunes 2011) and country specific initiatives (this article) that may be complemented by local initiatives.

This study specifically targeted the purchase of electrical appliances for domestic use, given that in the European Union (EU15 and EU27), major household appliances account for $30 \%$ of total domestic energy use (Bertold and Atanasiu 2007). In this regard, interventions aimed at increasing the purchase of energy efficient domestic appliances and reduce the associated domestic energy consumption, can have a high positive impact (Antunes, Gaspar, Lino 2012). The data analysed here, aimed at presenting differences between consumers across countries. This can support different national (and even regional or store) level energy efficiency interventions, deigned to implement policies in a way which is targeted to consumers in specific countries, rather than general interventions at European level. Based on this goal, the next section will present an overview of factors/variables for which data was collected in the study, and based on which the countries were compared.

\section{Determinants of electrical appliances choice and consideration of energy efficiency class}

Lay economic theories consider consumers decisions as rational and based on a cost-benefit analysis. This view has however been contested in the last decades, by showing consumers more as adaptive decision makers, influenced by an interaction between individual and situational variables (Payne, Bettman, Johnson 1993). In fact, if consumers followed a strict cost effective analysis, an increase in the purchase of energy efficient appliances would seem logical, as these could allow for a reduction in the domestic electricity bill. However, this is not the case and even when people report their decisions being solely determined by a cost-benefit analysis, other relevant factors may have also influenced their choice, outside conscious awareness.

Accordingly, there are individual factors, such as, the consumer's attitudes towards energy savings, social orientation, personal beliefs, norms and habits (Gaspar 2003), that may prevent them from choosing the most energy efficient options. These may interact with the consumers surrounding context (political, social, economic, etc.), creating other barriers. For example, Varone and Aebischer (2001) refer to failures in the market and institutions, in providing information that decreases consumers' information deficits. However, simply providing information is not sufficient to promote an energy efficient choice (DuPont 1998). In fact, consumers might not have the capacity, motivation or the opportunity, to take into consideration all the available information in their decisions (Dyer and Maronick 1988; Thøgersen 2000;
Yamamoto et al. 2008), independently of their educational degree (see e.g. Mills and Scleich 2009).

Apart from the referred individual factors, it is also important to include factors that are "outside" the individual. For example, some studies suggest that appliance's choice might be more dependent on their characteristics than on its retail cost (Yamamoto et al. 2008). Other studies have shown that for residential consumers, the more important characteristics were (Ball, Cullen, Gan 1982): the appliance's warranty; the long-term (energy and monetary) savings it allowed; perceived monetary and energy savings; energy services quality; perceived changes in comfort and convenience; characteristics allowing the possibility of control (e.g. thermostats). In accordance, Gaspar and Antunes (2011) performed a study to understand the factors/characteristics typically considered when purchasing electrical appliances, at a European level. Results indicated that although people referred to cost as the most important characteristic to consider when choosing an appliance, they also reported quality and energy consumption as the two most important factors after it. In addition, all of these were correlated positively with the consideration of energy efficiency class in their choices. Thus, when people considered cost and quality, they also considered the appliance's energy efficiency class in their choice and vice-versa. In addition to this, the analysis showed that psychosocial dimensions are also important in this regard (see e.g., Ozil et al. 2008). Environmental attitudes, for example, were shown to be negative predictors of energy efficiency class consideration. Accordingly, having a positive attitude with regard to environmental aspects in general and energy consumption in particular, that is, being sensitized about this, might actually be detrimental in the consideration of energy efficiency class in the choice. Differently, the frequent performance of environmental behaviours in various dimensions, directly related (e.g. use energy efficient light bulbs) or not (e.g. waste separation) with energy, was shown to be a positive predictor of it.

Another aspect that may influence consumers' energy efficient appliances choice, that is present in their social context, is the presence of technical staff/employees (Antunes et al. 2012). Given that they are present at the time of purchase (and in possible previous visits to the store, before this), they might have an influence over the consumer's choice. This influence can occur over the consideration of certain characteristics over others. Specifically, they can make the energy efficiency aspect and the information in this regard, salient to the consumers. Moreover, their interactions with the consumers can increase the probability that the information they provide will be integrated into the decision process (Anderson and Claxton 1982).

Based on all of this, it is clear that there may be various individual and situational/contextual factors, which may influence consumer's choice of electrical appliances. In accordance, the study presented here assessed this heterogeneity in the appliance's characteristics considered by consumers and their prior information search. In addition, it analysed individual and situational factors, such as for example: the motives underlying choice(s); variables related to the store employees/technicians interaction with customers; environmental attitudes; frequency of environmental behaviours (in 
general and energy related). The was is to present a country's "snapshot" based on these factors.

\section{Promotion 3E}

The research presented here was performed under the Intelligent Energy for Europe (IEE) funded project: "Promotion 3E The Promotion of Energy-Efficient Appliances in Europe." This project began in September 2008 with an overall objective to reduce energy consumption from the use of household appliances and equipment, by promoting the purchase and use of more energy efficient appliances. Other project aims included, for example, improvements in the quality and effectiveness of information made available to consumers at electrical appliances stores. To this end, the project partners carried out an assessment of consumer's appliance choices in order to allow for appropriate subsequent training of appliance store sales staff and supervisors. The project also included training needs assessment, with a goal of better enabling retailers to inform and persuade consumers in their consideration of the purchase and use of more energy efficient appliances.

In particular, the study aimed to understand the differences between European countries-the United Kingdom, Germany, Portugal, Greece, Poland, Spain and Italy-in a number of factors related with the choice of electrical appliances in general and specifically the consideration of characteristics associated with energy efficiency: energy efficiency class; energy consumption; power rating. As referred above, differently from Gaspar and Antunes (2011) that analysed results for an aggregated sample of European countries to provide a "snapshot" at the European level, the data presented here focuses on the profile of each country in particular and on a country comparison, focused on the variables mentioned.

\section{Method}

\section{Sample}

With regard to the survey sample, it comprised 211 store customers from Northern Ireland, 210 from Germany, 207 from Portugal, 246 from Greece, 210 from Poland, 138 from Spain and 210 from Italy, with a total of 1432 in-store surveys completed. For sample characterization purposes only, their socio-demographic characteristics for each country, can be seen in Table 1.

\section{Procedure}

In the first phase, qualitative semi-structured interviews were performed in the seven countries, as described in Gaspar and Antunes (2011). This was done to identify the major key factors/concerns and appliance characteristics that guided the choice process, that were subsequently included in the wider survey performed in the seven countries. Thus, these qualitative interviews served as a pre-test in this regard and allowed for the questionnaire construction.

Following from this, a survey was conducted between March and June 2009, in the seven countries. This was performed inside a set of electrical appliance stores that accepted to participate in a subsequent employees training in energy efficiency. This was focused on customers persuasion in order to consider the appliance's energy efficiency, when buying an appliance. Within each country at least three geographical areas/regions and three different stores were selected. In the United Kingdom, only Northern Ireland was included and three districts selected within it. The overall goal was not to collect a representative sample of the country's citizens but rather to collect a representative sample of the stores customers within each area selected, in each country. Given that not all country citizens may be customers of electrical appliances stores and are in the process of buying an appliance, more inclusive criteria for the sample selection were selected. Thus, although the participants were not representative of the country, they were representative of store customers of that country. This allowed the development of employee's training at each of these stores, targeted at the customers of those stores, across regions of each country. In addition, given that randomly recruiting participants at the store would not allow the samples to be completely equal, loose criteria for socio-demographic sampling quotas were used. This implied establishing a priori a minimum number of participants per store, with regard to age interval, gender and education level.

Based on these store selection criteria, customers were randomly approached at the entrance of each store and their informed consent to participate was requested. This survey included close-ended questions that referred mainly to the electrical appliance(s) the respondents were considering buying at the time they were approached to participate in the survey or in the near future. In this regard, studies in the literature either focus retrospectively on the last appliance purchased or based the study on purchase simulations. Differently, we aimed to obtain the information from the respondents at the point of purchase in the moment of choice, or at least considering to make the purchase in the near future. As referred by Gaspar and Antunes (2011; see also Antunes et al. 2012), this is a preferable approach. This is because the relevant appliance characteristics identified do not refer to those they think people should in general consider when buying or that they remember considering in the last purchase. Instead, they refer to the specific appliance they were considering buying at the moment. This allows acquiring information when the processes involved in their decisionmaking are taking place, prior to the decision, rather than after it or in a simulation.

\section{Instruments}

Examples of the questionnaire items can be found in Gaspar and Antunes (2011). The dimensions/factors assessed can be found Table 2, which also includes the scales that were constructed through the aggregation of some of the items used (responses in 1-to-5 Likert-type scales from 1- "Totally disagree" to 5 - "Totally agree," with 5 representing the highest value of the dimension assessed) and their corresponding reliability levels (Cronbach Alpha). 





Table 2. Dimensions/factors assessed through the questionnaire.

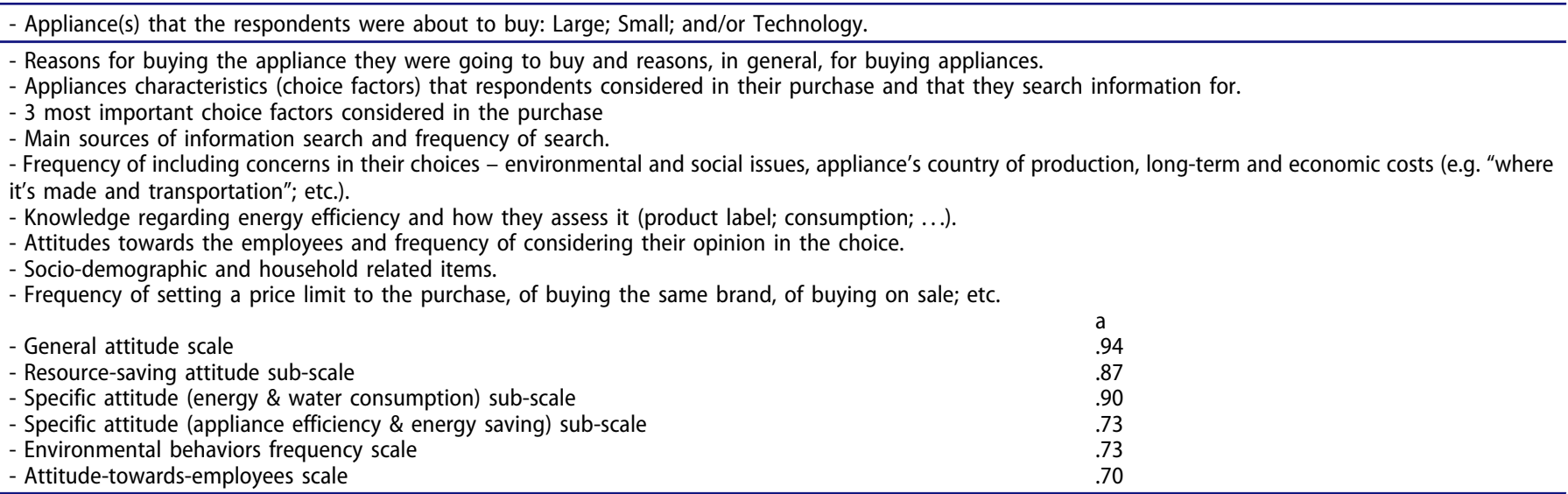

\section{Results and discussion}

Based on the SPSS 17 software, descriptive and inferential data analyses were performed, considering both on dichotomous variables (e.g. characteristic mentioned or not mentioned, i.e., considered or not considered in choice) and statistically validated scales (attitudes and behaviors) as shown in Table 2 (Cronbach's alpha).

\section{Environmental attitudes and behaviours - general and related with energy efficiency}

As shown in Table 3, the respondents showed positive environmental attitudes, both in general and specific, regarding consumption of water and energy and towards appliance's energy savings. Overall, this presents the respondents as people sensitized towards environmental conservation, and with a positive orientation towards energy efficiency issues and energy saving. In addition, MANOVA results showed significant differences between countries for: general attitude, $F(6$, $1301)=522.18, p=.000$; attitude regarding the energy appliances, $F(6,1301)=233.18, p=.000$; attitude regarding water and energy, $F(6,1301)=440, p=.000$; attitude regarding resources saving, $F(6,1301)=409.14, p=.000$; and perceived environmental behaviour, $F(6,1301)=31.90, p=.000$. In what concerns their overall environmental behavior, results showed that in all countries, respondents acknowledged performing environmental behaviours on an average of "sometimes," based on a frequency of performance scale from "never" (level 1) to "always" (level 5). Moreover, MANOVA results showed that there were significant differences between countries, in these, $F(6,86.65)=33.83, p=.000$. The country means for these variables are presented in Table 3.

From this table, it can be seen that the most positive attitudes were consistently reported in Portugal, Greece, Spain and Italy, irrespectively of the attitude target (on a Likert type scale from 1 to 5 , in which 5 represents the highest level of positivity). The United Kingdom presented more moderate results in this regard, with the lowest occurring for Germany and Poland. Differently, to what concerns environmental behaviours, Germany reported the highest reported frequency in performing these behaviours, followed by Spain and Portugal (based on scale from "never" (1) to "always" (5)). The lowest reported frequency was found in Poland. These results show a pattern that has also been found in the literature on environmental attitudes and behaviors, namely that positive attitudes do not necessarily imply a high frequency of environmental behaviours performance (see e.g. Ferreira Marques, PalmaOliveira, Marques and Ferreira, 1995).

\section{Type of electrical appliances considered for choice}

With regard to the electrical appliance choice in each country, more than $50 \%$ of respondents from Spain, Poland and Greece were considering choosing large appliances, followed by close to $30 \%$ of technology; respondents from Portugal were considering choosing almost the same percentage of large $(42.72 \%)$ and small appliances (40.78\%); respondents from the United Kingdom were considering choosing almost the same percentage of large appliances (35.55\%), small appliances $(29.86 \%)$ and technology $(34.60 \%)$, with the same happening to a lesser degree in Germany for large appliances (32.38\%), small appliances $(19.52 \%)$ and technology (31.43\%). Italy was the only country

Table 3. Results concerning general and specific environmental attitudes and behavior frequency.

\begin{tabular}{|c|c|c|c|c|c|c|c|c|c|c|}
\hline & \multicolumn{2}{|c|}{ Attitude - appliance energy savings } & \multicolumn{2}{|c|}{ Attitude - general } & \multicolumn{2}{|c|}{ Attitude - water \& energy } & \multicolumn{2}{|c|}{ Attitude - resources } & \multicolumn{2}{|c|}{ Environmental Behavior } \\
\hline & M & SD & M & SD & M & SD & M & SD & M & SD \\
\hline United Kingdom & 3.59 & .73 & 3.74 & .56 & 3.67 & .64 & 3.77 & .67 & 3.14 & .74 \\
\hline Germany & 1.86 & .78 & 1.70 & .62 & 1.70 & .62 & 1.72 & .73 & 3.56 & .49 \\
\hline Portugal & 4.19 & .61 & 4.45 & .50 & 4.48 & .49 & 4.42 & .57 & 3.46 & .74 \\
\hline Greece & 3.97 & .58 & 4.19 & .39 & 4.21 & .42 & 4.25 & .47 & 3.21 & .64 \\
\hline Poland & 3.45 & .93 & 3.21 & .65 & 3.19 & .70 & 3.15 & .74 & 2.82 & .58 \\
\hline Spain & 3.78 & .87 & 4.04 & .82 & 4.05 & .89 & 4.02 & .91 & 3.55 & .72 \\
\hline Italy & 4.20 & .63 & 4.31 & .68 & 4.19 & .88 & 4.41 & .64 & 3.34 & .67 \\
\hline
\end{tabular}


in which the percentage of technology purchases $(53.85 \%)$ was greater than the cumulative purchases of large appliances (32.21\%) together with small appliances (10.58\%). The percentages regarding the choice of electrical appliance(s) for each country can be seen in the next table.

\section{Motives for buying electrical appliances}

With respect to the reasons given for buying appliances in each country, these were more consistent for some than for others. Overall, the most frequently given reason for buying an electrical appliance was substituting an old one that broke. The only exception was the Polish respondents, in which this was the second reason, with the first reason being that they did not have one $(30.33 \%)$. This latter reason was second for all the other countries. The third most frequently given reason for all the countries was to acquire a better quality/technology appliance. The reasons related with less energy consumption were in fourth place for the United Kingdom (5.21\%), Germany (11.61\%) and Poland (9.95\%), in fifth place for Greece (5.83\%), Spain (3.68\%) and Italy (4.96\%), and in eighth place for Portugal (1.36\%). The percentages regarding the reasons for the choice of electrical appliance(s) for each country can be seen in Table 4 .

\section{Characteristics considered in choice}

Regarding country differences in the choice factors, Table 5 presents the three highest percentages of characteristic's consideration in each country. Results show that there was consistency between countries, being these mainly related to cost and quality. However, in terms of frequency of consideration, cost for example, was much more considered in The United Kingdom (74.40\%) than in any of the other countries, with the same happening for quality in Greece (71.10\%). In addition to cost and quality, energy consumption also emerged as a characteristic frequently considered in choice, in Germany, Portugal and Spain. Finally, warranty was also frequently considered in Greece and Italy but not in the other countries.

Considering all the characteristics and not only the top three, a Chi-Square test analysis showed that differences arise especially between the ones related with energy and water consumption. Germany was the country that considered significantly more than expected - based on the standardized adjusted residual value-characteristics such as power rating, water consumption, energy consumption and the energy efficiency class. Greece also considered significantly more than expected characteristics such as power rating, energy consumption and energy efficiency class. In addition, Portugal considered the energy consumption significantly more than expected. Differently, Poland, Spain and Italy considered energy consumption significantly less than expected; the United Kingdom and Italy considered water consumption significantly less than expected; the United Kingdom and Spain considered the energy efficiency class significantly less than expected. These and other results can be seen in Table 7.

With respect to the information search regarding the appliance's characteristics, prior to choice, differences were also found between characteristics related with energy and water consumption. Germany and Greece respondents reported searching information significantly more than expected for the same most frequently considered characteristics, mentioned above. Italy respondents also reported searching more than expected information related to the energy efficiency class. Differently, the United Kingdom and Poland respondents reported searching significantly less than expected, information related to energy consumption; respondents from the United Kingdom and Italy considered significantly less than expected, the water consumption aspect; respondents from the United Kingdom, Portugal, Poland and Spain searched significantly less than expected, information related to energy efficiency class; finally, respondents from Ireland and Portugal reported searching significantly less than expected information related to water consumption. These results can be seen in Table 8 .

Table 4. Types of electrical appliances chosen by country (\%).

\begin{tabular}{|c|c|c|c|c|c|c|c|}
\hline Appliance type & Ireland & Germany & Portugal & Greece & Poland & Spain & Italy \\
\hline Large appliance & 35.55 & 32.38 & 42.72 & 51.63 & 58.39 & 58.39 & 32.21 \\
\hline Small appliance & 29.86 & 19.52 & 40.78 & 13.41 & 11.68 & 11.68 & 10.58 \\
\hline Technology & 34.60 & 31.43 & 16.02 & 31.30 & 29.93 & 29.93 & 53.85 \\
\hline Large \& small appliance & 0 & 1.90 & .49 & 1.63 & 0 & 0 & 0 \\
\hline Large appliance \& technology & 0 & 6.67 & 0 & 1.22 & 0 & 0 & 2.40 \\
\hline Small appliance \& technology & 0 & 4.76 & 0 & 0 & 0 & 0 & 0 \\
\hline All types & 0 & 3.33 & 0 & .81 & 0 & 0 & .96 \\
\hline
\end{tabular}

Table 5. Reasons for choosing electrical appliances, by country.

\begin{tabular}{|c|c|c|c|c|c|c|c|}
\hline Reasons & United Kingdom & Germany & Portugal & Greece & Poland & Spain & Italy \\
\hline I don't have one & 19.91 & 17.56 & 30.32 & 25.07 & 30.33 & 30.88 & 27.27 \\
\hline The old one broke & 51.18 & 34.23 & 37.10 & 31.78 & 20.85 & 46.32 & 34.71 \\
\hline It's on promotion/sale & 2.37 & .60 & 0 & 1.46 & 3.32 & 3.68 & 1.65 \\
\hline Less water consumption & 0 & 4.17 & 0 & 1.46 & 1.42 & 0 & 1.65 \\
\hline Less energy consumption & 5.21 & 11.61 & 1.36 & 5.83 & 9.95 & 3.68 & 4.96 \\
\hline Better quality/technology & 14.69 & 17.86 & 11.76 & 19.53 & 20.85 & 7.35 & 12.40 \\
\hline All my friends have one & 0 & 3.27 & .90 & 0 & 1.42 & 0 & .83 \\
\hline Adjusted capacity to new needs & 1.90 & 7.44 & 7.69 & 10.50 & 1.90 & 6.62 & 7.44 \\
\hline New home dimensions & .47 & 2.08 & 3.62 & 2.62 & 9.48 & 0 & 4.96 \\
\hline New house decoration & 2.37 & .60 & 1.81 & 1.46 & .47 & 1.47 & 2.48 \\
\hline
\end{tabular}


Table 6. Percentages for the three most important characteristics for choosing electrical appliances by country.

\begin{tabular}{|c|c|c|c|c|c|c|c|}
\hline & United Kingdom & Germany & Portugal & Greece & Poland & Spain & Italy \\
\hline 1st & Cost $(74.40 \%)$ & $\begin{array}{l}\text { Price vs Quality } \\
(68.10 \%)\end{array}$ & Quality (42.50\%) & $\begin{array}{l}\text { Quality } \\
\text { (71.10\%) }\end{array}$ & Cost $(45.20 \%)$ & Price vs Quality (28.80\%) & $\begin{array}{l}\text { Price vs Quality } \\
(23.80 \%)\end{array}$ \\
\hline 2nd & Quality (37.90\%) & Quality (58.60\%) & Cost (37.70\%) & Cost $(62.60 \%)$ & Quality (27.60\%) & $\begin{array}{l}\text { Technological innovation } \\
(12.30 \%)\end{array}$ & Quality $(17.10 \%)$ \\
\hline
\end{tabular}

Table 7. Within-country percent (\%) of characteristic consideration for choice.

\begin{tabular}{|c|c|c|c|c|c|c|c|c|}
\hline & United Kingdom & Germany & Portugal & Greece & Poland & Spain & Italy & Chi-square \\
\hline Power rating & $6.60^{\mathrm{b}}$ & $25.20^{\mathrm{a}}$ & $4.30^{\mathrm{b}}$ & $36.60^{a}$ & 10.50 & 10.90 & $3.80^{\mathrm{b}}$ & $x^{2}(6)=165.34$ \\
\hline Capacity & $6.20^{\mathrm{b}}$ & 12.90 & $2.40^{\mathrm{b}}$ & $28.90^{\mathrm{a}}$ & $19^{a}$ & 8 & $2.90^{\mathrm{b}}$ & $x^{2}(6)=119.12$ \\
\hline Technological innovation & 11.80 & 15.70 & $.50^{\mathrm{b}}$ & $30.10^{a}$ & $7.10^{\mathrm{b}}$ & 12.30 & 11.90 & $x^{2}(6)=98.59$ \\
\hline Water consumption & $3.80^{\mathrm{b}}$ & $26.70^{\mathrm{a}}$ & 8.20 & 12.60 & 5.60 & 2.80 & $3.80^{\mathrm{b}}$ & $x^{2}(6)=86.99$ \\
\hline Energy consumption & 19.40 & $46.20^{\mathrm{a}}$ & $36.70^{\mathrm{a}}$ & $37.80^{\mathrm{a}}$ & $8.60^{b}$ & $15.90^{\mathrm{b}}$ & $5.70^{\mathrm{b}}$ & $x^{2}(6)=168.05$ \\
\hline Energy efficiency class & $9^{b}$ & $21.40^{\mathrm{a}}$ & $5.80^{\mathrm{b}}$ & $27.60^{a}$ & 10 & $6.50^{\mathrm{b}}$ & 19 & $x^{2}(6)=72.16$ \\
\hline Price vs. Quality & 30.80 & $68.10^{\mathrm{a}}$ & $14^{b}$ & 34.60 & 27.10 & 28.80 & $23.80^{\mathrm{b}}$ & $x^{2}(6)=166.20$ \\
\hline Quality & 37.90 & $58.60^{\mathrm{a}}$ & 42.50 & $71.10^{\mathrm{a}}$ & $27.60^{\mathrm{b}}$ & $8^{b}$ & $17.10^{\mathrm{b}}$ & $x^{2}(6)=248.86$ \\
\hline Cost & $74.40^{\mathrm{a}}$ & 45.20 & 37.70 & $62.60^{a}$ & 45.20 & $4.30^{\mathrm{b}}$ & $10^{b}$ & $x^{2}(6)=305.13$ \\
\hline Warranty & 13.30 & $22.90^{\mathrm{a}}$ & $4.80^{b}$ & $43.90^{\mathrm{a}}$ & $5.20^{\mathrm{b}}$ & $0^{b}$ & 14.80 & $x^{2}(6)=209.55$ \\
\hline Customer support & $0^{\mathrm{b}}$ & $13.80^{\mathrm{a}}$ & 5.80 & $17.50^{\mathrm{a}}$ & 8.10 & $0^{\mathrm{b}}$ & 5.70 & $x^{2}(6)=73.77$ \\
\hline Brand and/or Model & 17.10 & 9 & $23.70^{\mathrm{a}}$ & $24.40^{\mathrm{a}}$ & 12.40 & $0^{\mathrm{b}}$ & $4.80^{\mathrm{b}}$ & $x^{2}(6)=82.03$ \\
\hline Dimensions & 5.20 & 6.70 & 8.70 & $21.50^{a}$ & $15.20^{a}$ & $0.70^{\mathrm{b}}$ & $2.40^{\mathrm{b}}$ & $x^{2}(6)=81.99$ \\
\hline Design/Colour/Decoration & $23.20^{\mathrm{a}}$ & 11 & 18.40 & 16.30 & $20.50^{a}$ & $0^{b}$ & $.50^{\mathrm{b}}$ & $x^{2}(6)=84.58$ \\
\hline Accessories & $.50^{\mathrm{b}}$ & 5.70 & $0.50^{\mathrm{b}}$ & 6.10 & $8.60^{\mathrm{a}}$ & $0^{b}$ & 2.90 & $x^{2}(6)=38.23$ \\
\hline Number of functions & 14.20 & 8 & 11.70 & 12.20 & $27.10^{a}$ & $0^{\mathrm{b}}$ & $2.90^{\mathrm{b}}$ & $x^{2}(6)=87.46$ \\
\hline Cleanliness & $0^{\mathrm{b}}$ & $4.80^{\mathrm{a}}$ & .50 & $4.90^{\mathrm{a}}$ & 4.30 & 0 & .50 & $x^{2}(6)=30.93$ \\
\hline User friendliness & 15.60 & $38.10^{\mathrm{a}}$ & 14 & $24.80^{\mathrm{a}}$ & $6.70^{\mathrm{b}}$ & $0^{b}$ & $8.60^{\mathrm{b}}$ & $x^{2}(6)=136.59$ \\
\hline Users' opinions & 2.80 & 6.70 & $0^{\mathrm{b}}$ & 4.90 & $12.40^{\mathrm{a}}$ & $0^{\mathrm{b}}$ & 1.40 & $x^{2}(6)=57.69$ \\
\hline Safety & 8.10 & 7.10 & $1^{b}$ & 8.50 & $12.90^{\mathrm{a}}$ & $0^{\mathrm{b}}$ & 8.10 & $x^{2}(6)=35.06$ \\
\hline Other & $0^{b}$ & 1.40 & $23.20^{\mathrm{a}}$ & 1.60 & 1.90 & $0^{b}$ & $0^{b}$ & $x^{2}(6)=224.88$ \\
\hline
\end{tabular}

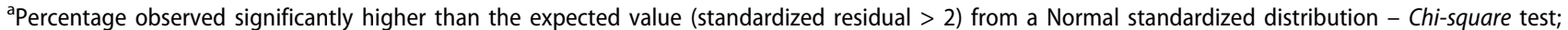

${ }^{b}$ Percentage observed significantly lower than the expected value (standardized residual < 2) from a Normal standardized distribution - Chi-square test; For values with no asterisk the percentage observed $\approx$ expected.

Table 8. Within-country percent (\%) of type of information searched before buying.

\begin{tabular}{|c|c|c|c|c|c|c|c|c|}
\hline & United Kingdom & Germany & Portugal & Greece & Poland & Spain & Italy & Chi-square \\
\hline Power rating & $.90^{\mathrm{b}}$ & $29^{a}$ & $7.70^{\mathrm{b}}$ & $25.20^{\mathrm{a}}$ & $4.80^{b}$ & 11.60 & 12.90 & $x^{2}(6)=120.57$ \\
\hline Capacity & $1.40^{\mathrm{b}}$ & $18.10^{\mathrm{a}}$ & $3.90^{\mathrm{b}}$ & $27.60^{\mathrm{a}}$ & $.50^{\mathrm{b}}$ & 9.40 & $16.70^{\mathrm{a}}$ & $x^{2}(6)=135.09$ \\
\hline Technological innovation & 7.60 & $15.20^{\mathrm{a}}$ & $1^{\mathrm{b}}$ & $15.40^{\mathrm{a}}$ & $1.40^{\mathrm{b}}$ & 9.40 & $17.60^{\mathrm{a}}$ & $x^{2}(6)=66.26$ \\
\hline Water consumption & $.50^{\mathrm{b}}$ & $21.40^{\mathrm{a}}$ & $1^{b}$ & 3.70 & 7.60 & 2.90 & 8.1 & $x^{2}(6)=106.58$ \\
\hline Energy consumption & $2.40^{\mathrm{b}}$ & $41.40^{\mathrm{a}}$ & 15.50 & $24^{a}$ & $1^{\mathrm{b}}$ & 10.90 & 18.6 & $\hat{x}^{2}(6)=174.49$ \\
\hline Energy efficiency class & $1.40^{\mathrm{b}}$ & $23.80^{\mathrm{a}}$ & $3.90^{\mathrm{b}}$ & $17.90^{\mathrm{a}}$ & $1.90^{\mathrm{b}}$ & $3.60^{\mathrm{b}}$ & $29^{a}$ & $x^{2}(6)=155.84$ \\
\hline Price vs. Quality & $6.60^{\mathrm{b}}$ & $50^{\mathrm{a}}$ & $2.90^{\mathrm{b}}$ & 19.10 & $1^{\mathrm{b}}$ & 13.80 & $44.30^{\mathrm{a}}$ & $x^{2}(6)=308.34$ \\
\hline Quality & $13.30^{\mathrm{b}}$ & $51.90^{\mathrm{a}}$ & 20.80 & $40.70^{\mathrm{a}}$ & $3.80^{\mathrm{b}}$ & $10.10^{\mathrm{b}}$ & 30 & $\hat{x}^{2}(6)=197.27$ \\
\hline Cost & $14.20^{\mathrm{b}}$ & $45.70^{\mathrm{a}}$ & 29.50 & $41.10^{\mathrm{a}}$ & $10.50^{\mathrm{b}}$ & $4.30^{\mathrm{b}}$ & 31.40 & $x^{2}(6)=148.27$ \\
\hline Warranty & $.90^{\mathrm{b}}$ & $22.90^{\mathrm{a}}$ & $.50^{\mathrm{b}}$ & $23.20^{\mathrm{a}}$ & $1.90^{\mathrm{b}}$ & $0^{\mathrm{b}}$ & $18.10^{\mathrm{a}}$ & $x^{2}(6)=164.68$ \\
\hline Customer support & $0^{\mathrm{b}}$ & $13.30^{\mathrm{a}}$ & $0^{\mathrm{b}}$ & $9.30^{\mathrm{a}}$ & $0^{\mathrm{b}}$ & $0^{\mathrm{b}}$ & $15.20^{\mathrm{a}}$ & $\hat{x}^{2}(6)=108.96$ \\
\hline Brand and/or Model & $3.80^{\mathrm{b}}$ & $16.70^{\mathrm{a}}$ & 11.60 & $16.70^{\mathrm{a}}$ & $1.90^{\mathrm{b}}$ & $0^{\mathrm{b}}$ & $21^{\mathrm{a}}$ & $x^{2}(6)=82.96$ \\
\hline Dimensions & $0^{\mathrm{b}}$ & $13.80^{\mathrm{a}}$ & $2.90^{\mathrm{b}}$ & $19.50^{\mathrm{a}}$ & $1.40^{\mathrm{b}}$ & $0^{\mathrm{b}}$ & 11.40 & $\hat{x}^{2}(6)=111.13$ \\
\hline Design/Color/Decoration & $.50^{\mathrm{b}}$ & $16.20^{\mathrm{a}}$ & 1.90 & 6.50 & $0^{\mathrm{b}}$ & $0^{\mathrm{b}}$ & 5.20 & $\hat{x}^{2}(6)=94.66$ \\
\hline Accessories & .90 & $8.10^{a}$ & 2.40 & 4.50 & 1 & 1.40 & 2.40 & $x^{2}(6)=27.63$ \\
\hline Number of functions & $.50^{\mathrm{b}}$ & $20.50^{\mathrm{a}}$ & 7.70 & 7.30 & $1.40^{\mathrm{b}}$ & $1.40^{\mathrm{b}}$ & $12.90^{\mathrm{a}}$ & $x^{2}(6)=91.05$ \\
\hline Cleanliness & 0 & $5.70^{\mathrm{a}}$ & .50 & $4.50^{\mathrm{a}}$ & 0 & 0 & 1.90 & $x^{2}(6)=37.09$ \\
\hline User friendliness & $.50^{\mathrm{b}}$ & $27.10^{\mathrm{a}}$ & $.50^{\mathrm{b}}$ & $11.80^{\mathrm{a}}$ & $.50^{\mathrm{b}}$ & $0^{\mathrm{b}}$ & 7.10 & $\hat{x}^{2}(6)=184.45$ \\
\hline Users' opinions & $.50^{\mathrm{b}}$ & $11.40^{\mathrm{a}}$ & $1^{\mathrm{b}}$ & 2.40 & 4.80 & $0^{\mathrm{b}}$ & 5.20 & $x^{2}(6)=53.17$ \\
\hline Safety & $0^{\mathrm{b}}$ & $8.10^{\mathrm{a}}$ & $0^{\mathrm{b}}$ & 3.70 & 1.90 & $0^{b}$ & $7.10^{\mathrm{a}}$ & $\hat{x}^{2}(6)=42.28$ \\
\hline Other & $0^{\mathrm{b}}$ & 1 & $14.50^{\mathrm{a}}$ & 5.30 & $0^{b}$ & $0^{b}$ & $.50^{\mathrm{b}}$ & $\hat{x}^{2}(6)=115.18$ \\
\hline
\end{tabular}

aPercentage observed significantly higher than the expected value (standardized residual > 2) from a Normal standardized distribution - Chi-square test;

${ }^{b}$ Percentage observed significantly lower than the expected value (standardized residual $<2$ ) from a Normal standardized distribution - Chi-square test; For values with no asterisk the percentage observed $\approx$ expected.

\section{Attitudes towards store employees/technicians}

Regarding the variables related to the store employees/technicians interaction with customers, overall in every country the mean values for general attitude towards the store employees/ technicians and the perception of the importance of their help, were moderately to highly positive (between 3 , the midpoint of the 1 to 5 scale, and 4). The lowest values were found in Poland, although moderate. The highest positivity was found in Germany and Portugal, followed by Spain. The MANOVA test results showed these differences to be significant for both the general attitude, $\mathrm{F}(6,540.59)=25.80, p=$ .000 ; and for the perceived importance, $\mathrm{F}(6,1472.47)=31.58$, $p=.000$. The country means for these variables are presented in Table 9. 
Table 9. Mean values for the general attitude towards the store employees/technicians and the perception of the importance of their help, for each country.

\begin{tabular}{|c|c|c|c|c|c|c|c|c|c|c|c|c|c|c|}
\hline & \multicolumn{2}{|c|}{ United Kingdom } & \multicolumn{2}{|c|}{ Germany } & \multicolumn{2}{|c|}{ Portugal } & \multicolumn{2}{|c|}{ Greece } & \multicolumn{2}{|c|}{ Poland } & \multicolumn{2}{|c|}{ Spain } & \multicolumn{2}{|c|}{ Italy } \\
\hline & $M$ & SD & $M$ & SD & $M$ & SD & $M$ & SD & $M$ & SD & $M$ & SD & $M$ & SD \\
\hline $\begin{array}{l}\text { General attitude } \\
\text { Tech help }\end{array}$ & $\begin{array}{l}3.34 \\
3.00\end{array}$ & $\begin{array}{l}.70 \\
1.20\end{array}$ & $\begin{array}{l}3.72 \\
3.77\end{array}$ & $\begin{array}{l}.67 \\
1.16\end{array}$ & $\begin{array}{l}3.66 \\
3.97\end{array}$ & $\begin{array}{l}.53 \\
.90\end{array}$ & $\begin{array}{l}3.45 \\
3.64\end{array}$ & $\begin{array}{l}.50 \\
.92\end{array}$ & $\begin{array}{l}3.05 \\
2.87\end{array}$ & $\begin{array}{l}.78 \\
1.13\end{array}$ & $\begin{array}{l}3.61 \\
3.81\end{array}$ & $\begin{array}{l}.67 \\
1.03\end{array}$ & $\begin{array}{l}3.48 \\
3.56\end{array}$ & $\begin{array}{l}.72 \\
1.21\end{array}$ \\
\hline
\end{tabular}

\section{Implications for store employees training and national/local policies}

Based on the results, some guidelines regarding store employees training can be proposed. These can help sellers of the various countries, in influencing customers' in considering the energy efficiency characteristic and specifically class A appliances over other classes.

First, despite the variety of electrical appliances types that the respondents were about to buy, the reasons to buy them were similar, with them reporting mainly the need to replace an old one that broke, followed by "not having one." This last reason, of having never chosen a particular type of appliance before, allows for a "window of opportunity". This is because they can be more easily persuaded to consider energy savings and class A choice, than people that have made the decision before and did not include these in their choice process. For those that have already been through a choice process before and who were replacing one appliance that broke, choosing a better quality/technology appliance or an appliance with adjusted capacity to new needs (with these three reasons for choice also frequently identified), the promotion of electrical appliances labelled class A and persuasion toward the consideration of this at the time of purchase can also be achieved (in this regard, see also Young 2008).

In accordance, the fact that in the various countries a moderate to high frequency of environmental behaviors performance was reported, may make the responders predisposed to consider the resource savings aspect and to be persuaded in this regard, i.e., they can be persuaded to be consistent in their behaviors in these environmental dimensions. Thus, a persuasion message to promote the choice of class A appliances may influence customers to view this choice as an "extension" of their pro-environmental behaviors to the area of ecological purchase domain of electrical appliances (associated with an idea similar to "If I already perform environmental behaviors in some areas, then I should be consistent and make my choice in an ecological way").

In this regard, the information that can be presented to customers in stores should be specifically targeted towards their behavior, namely the specific consequences for the customers and their families of buying a class A appliance, in terms of energy and water savings. This is an aspect already considered as a choice factor by the customers, although not considered frequently enough in choice, as mentioned before. Thus, this information can include consequences referring the economic savings on one side and the appliance efficiency on another, given that the two most important choice factors for the customers were the appliance cost and its quality. Therefore, the former two aspects (energy and water savings) can be associated with these latter two aspects (cost and quality) in a way that increases the perceived benefits in choosing the appliance and include the consideration of class A in their habitual choice.

In addition to these aspects, it is also important to refer the implications of results regarding the respondent's perception of the stores employees. Customers had a general moderate to high positive opinion regarding the employees, having considered that they give useful information, that their opinion is important and that the information they provide can be trusted. These aspects already make customers predisposed to accept the employees' opinions and thus, attribute to them a high importance in this regard. Specifically, employees are present at the point of purchase, a critical moment to persuade customers to consider the energy efficiency aspect. Still, if interventions are designed to increase customers' positive attitudes towards the employees, especially for the countries in which these were slightly lower, this may also increase the probability that their information is taken into consideration for choice.

Overall, given the existence of similarities and differences between countries, the training content should be designed in a standard way for all countries to what concerns the similarities (i.e. similar procedures must be used). At the same time, it should be adapted to the differences through specific procedures for each country and tailored to specific groups as defined by Gaspar and Antunes (2011) based on socio-demographic profiles and/or other differentiating characteristics. With regard to similarities found, results showed consistency between the top characteristics considered in choice, across countries, namely quality, cost or the balancing between the appliance's price and its quality. This was found for all countries and also at the European level, considering the countrie's aggregated results, as found in Gaspar and Antunes (2011). The implication of this is that, not only the employees should have that in mind when interacting with costumers but also that the energy efficiency and energy consumption (and even water consumption) aspects aspects may be associated with quality and cost, to present a more persuasive argument. This can be achieved for example, by comparing two similar models from the same brand with similar characteristics but different in the energy efficiency class. This could imply that, under this scenario, a higher efficiency appliance could provide more savings, if the same type of appliance but of a lower efficiency class was used by the consumer. Also, Gaspar and Antunes (2011) showed that people associate a high energy class with higher quality and vice-versa. Given that in each country quality was considered a top characteristic, making salient this connection between quality and efficiency may persuade consumers in each country in considering efficiency in their choice through association. This strategy may have the highest potential in Germany, Portugal and Spain, where the energy consumption aspect was at the top characteristics 
considered. Moreover, in Spain this can be associated with an innovation aspect, as this was also important for part of the Spanish participants. An additional aspect to consider is that the European level results presented by Gaspar and Antunes (2011) derived implications for policy based on the fact that on average the survey respondents referred that were going to purchase a large appliance when inquired. Differently, the results presented here show that this was not the case for all countries, given that in Italy and somewhat in the United Kingdom and Germany, the majority of appliances that were being considered for purchase were "technology" appliances (e.g. LCD), followed by small appliances. Although overall the same persuasion strategy can be used in this case, the employees training in each country should also consider this difference. Accordingly, the content of the energy label for example, is partly different from larger appliances and thus, the use of energy labels as an "instrument" for persuasion (see, Thøgersen 2000; Mills and Scleich 2009; Gaspar and Antunes 2011) should take this difference into consideration.

In order to "invite" energy efficient technology into households it is important to understand how people make decisions about the technology they buy and use. Even if western culture may share some common features, it is important to understand that different historical paths and events may lead to different levels of adjustment to societal changes towards sustainability. This may be reflected on differences between countries regarding consumer motivations and choice processes in electrical appliances purchase (Gaspar and Antunes 2011), in electrical equipment purchase and installation (e.g. Bertoldi and Atanasiu 2008) and adoption of innovative equipment in this regard (e.g. Valentová, Quicheron, Bertoldi 2015), as well as on people behavior regarding energy consumption (e.g. Ferreira Marques et al. 1995).

In accordance, this study aimed to respond to this latter need, by exploring country differences and similarities, with regard to the characteristics considered by purchasers, in the choice of electrical appliances in general; and focusing on the consideration of characteristics associated with energy efficiency: energy efficiency class; energy consumption; power rating. Moreover, it assessed information search regarding these same characteristics, prior to the appliance's choice, along with purchase motives, and variables related to the store employees/technicians interaction with customers.

All the aspects studied referred to an area where energy efficiency and consumer behavior areas overlap. Therefore, this can aid stakeholders and policy makers in promoting and increasing the purchase of energy-efficient appliances and in reducing households' energy consumption, thus contributing to the European Horizon 2020 targets. In this regard, it provides a valuable resource for policy makers, as it was performed right before or at the point of purchase, rather than a long time before or after the purchase, as in most studies.

Overall, the data collected here for seven European countries - the United Kingdom, Germany, Portugal, Greece, Poland, Spain and Italy - provides a better understanding of the factors that underlie consumers' decisions, when choosing domestic electrical appliances in each country. It is our contention that this can be used as baseline data to support national/regional, and even store level energy efficiency interventions/communication and policies, tailored to the factors that are mostly considered by customers in these countries.

Accordingly, in order to implement European policies in each country we need first to understand their specificities, so that these policies can be adapted to these. This can allow tailoring communication messages and communication channels in a way that increases people's predisposition to attend to and elaborate on the information and set other necessary situational and individual characteristics, and ultimately to change behavior. For instance, the study results seem to imply that sales personnel may be a better persuasion source in Portugal than in Poland, as the attitudes towards them were more positive in the former than in the latter. Also, using arguments related to water saving may be a good persuasive information complement to information on energy efficiency, for selling washing machines in Germany, but not in the United Kingdom or Spain. Therefore, country specificities should allow policy makers to devise their own in-store sales personnel training adapted to each country's general and specific environmental attitudes, information search patterns and appliance's characteristics considered in choice.

\section{Conclusions}

Previous studies have shown that it is important to understand the relationship between the appliances characteristics considered in choice (and in particular the characteristics related to energy efficiency) and the associated consumer profiles based on socio-demographic and other characteristics. This supports macro level communication and interventions, allowing policy makers at the European level, to have crosscountry initiatives and target various types of consumers, based on their socio-demographic and psychosocial profiles. However, this information is incomplete without more specific information for each country, which can allow policy makers at the country and regional levels, to tailor their communication and intervention strategies, to the cultural specificities of their citizens.

\section{Notes}

1. The EU Energy Label framework establishes the requirement to provide information on the consumption of energy, and of other essential information (e.g. noise produced by the appliance; water consumption; ...), of household appliances at the point of sale, thereby allowing consumers to choose more energy-efficient appliances. The label includes a rating including a set of energy efficiency classes from $A$ to $G$, with $A$ being the most energy efficient, $G$ the least efficient. More recently, more specific ratings have been given within each rank, by adding a + sign (e.g. $\mathrm{A}^{+++}$). The EU Energy label was first created by the Council Directive 92/ 75/EEC of 22 September 1992, being regulated by directives specifically concerning different household appliances, namely refrigerators, freezers and their combinations; electric ovens; airconditioners; dishwashers; lamps; washer-dryers, tumble dryers and washing machines. The legal framework was recently recast: the Directive 92/75/EEC was repealed with effect from July 2011, being replaced by Directive 2010/30/EU of 19 May 2010. More information can be obtained here: http://www.energy.eu/focus/ energy-label.php 
2. This question was asked in a different way in the United Kingdom (income interval) and thus the results are presented in a different format.

3. This value was higher for Spain than for other countries, due to the presence of outlier results (e.g. 60000 Euros) which increased the mean income. For this reason, median values are also presented for each country.

\section{Funding}

William James Center for Research, ISPA- Instituto Universitário is supported by the FCT Grant No. UID/PSI/04810/2013.

\section{ORCID}

Rui Gaspar (D) http://orcid.org/0000-0002-0943-6658

\section{References}

Anderson, D., and J. Claxton. 1982. Barriers to consumer choice of energy efficient products. Journal of Consumer Research 9:163-70.

Antunes, D., R. Gaspar., and J. Lino. 2012. "Energy efficient appliances and energy efficient behaviours: from consumer's assessment to behaviour intervention." In Energy Efficiency: Methods, Limitations and Challenges, ed. E. F. S Cavalcanti and M. R. Barbosa, New York; Nova Science Publishers.

Atanasiu, B. and P. Bertoldi. 2010. Latest assessment of residential electricity consumption and efficiency trends in the european union. International Journal of Green Energy 7(5):552-575.

Ball, R., R. Cullen, and, C. Gan. 1982. The diffusion of energy efficiency innovations among residential energy consumers. New Zealand Economic Papers 33:115-35.

Bertoldi, P. and B. Atanasiu. 2007. Electricity Consumption and efficiency trends in the enlarged European Union-status report 2006. European Commission Directorate-General Joint Research Centre; Institute for Environment and Sustainability, Italy.

Bertoldi, P. and B. Atanasiu. 2008. Characterization of residential lighting consumption in the enlarged european union and policies to save energy. International Journal of Green Energy 5(1-2):15-34. DOI: $0.1080 / 15435070701839397$

Bertoldi, P. and B. Atanasiu. 2011. An in-depth analysis of the electricity end-use consumption and energy efficiency trends in the tertiary sector of the european union. International Journal of Green Energy 8(3):306-31.
DuPont, P. 1998. Energy policy and consumer reality: The role of energy in the purchase of household appliances in the U.S. and Thailand [dissertation]. University of Delaware, Delaware.

Dyer, R. and T. Maronick. 1988. An evaluation of consumer awareness and use of energy labels in the purchase of major appliances: a longitudinal analysis. Journal of Public Policy \& Marketing 7:83-97.

Ferreira Marques, J., J. M. Palma-Oliveira, J. F. Marques, and M. B. Ferreira. 1995. "Subgroup comparisons." In The Psychological and Social Determinants of Environmental Attitudes and Behaviours: International comparison, ed. C. Levy-Leboyer, M. Bonnes, K. Pawlik, J. Ferreira Marques, and J. Chase, EU Project Report, Brussels.

Gaspar, R. 2013. Understanding the reasons for behavioral failure: a process view of psychosocial barriers and constraints to pro-ecological behavior. Sustainability 5:2960-75.

Gaspar, R. and D. Antunes. 2011. Energy efficiency and appliances purchase in Europe: consumer profiles and choice determinants Energy Policy 39:7335-46.

Gaspar, R., J. M. Palma-Oliveira, and V. Corral-Verdugo. 2010. "Why do people fail to act? Situational barriers and constraints on ecological behaviour." In Psychological Approaches to Sustainability: Current Trends in Research, Theory and Practice, ed. V. Corral-Verdugo, C. García-Cadena, and M. Frías-Armenta, New York: Nova Science Publishers.

Haar, N. and G. Theyel. 2006. U.S. electric utilities and renewable energy: Drivers for adoption. International Journal of Green Energy 3(3):271-81.

Mills, B., and J. Scleich. 2009. What's driving energy efficient appliance label awareness and purchase propensity? Fraunhofer Institute for Systems and Innovation Research (Fraunhofer ISI), Karlsruhe.

Ozil, E., V. I. Ugursal, U. Akbulut and A. Ozpinar. 2008. Renewable energy and environmental awareness and opinions: A survey of university students in Canada, Romania, and Turkey. International Journal of Green Energy 5(3):174-88.

Payne, J. W., J. R. Bettman., and E. J. Johnson. 1993. The Adaptive Decision Maker. Cambridge: Cambridge University Press.

Roosa, S. A. 2007. Energy policy and sustainability in sunbelt cities in the united states. International Journal of Green Energy 4(2):173-96.

Thøgersen J. 2000. Psychological determinants of paying attention to eco-labels in purchase decisions: Model development and multinational validation. Journal of Consumer Policy 23:285-313

Valentová, M., M. Quicheron and P. Bertoldi. 2015. LED projects and economic test cases in Europe. International Journal of Green Energy 12(8):843-51.

Yamamoto, Y., A. Suzuki., Y. Fuwa., and T. Sato. 2008. Decision-making in electrical appliance use in the home. Energy Policy 36:1679-86.

Young, D. 2008. When do energy-efficient appliances generate energy savings? Some evidence from Canada. Energy Policy 36:34-46. 